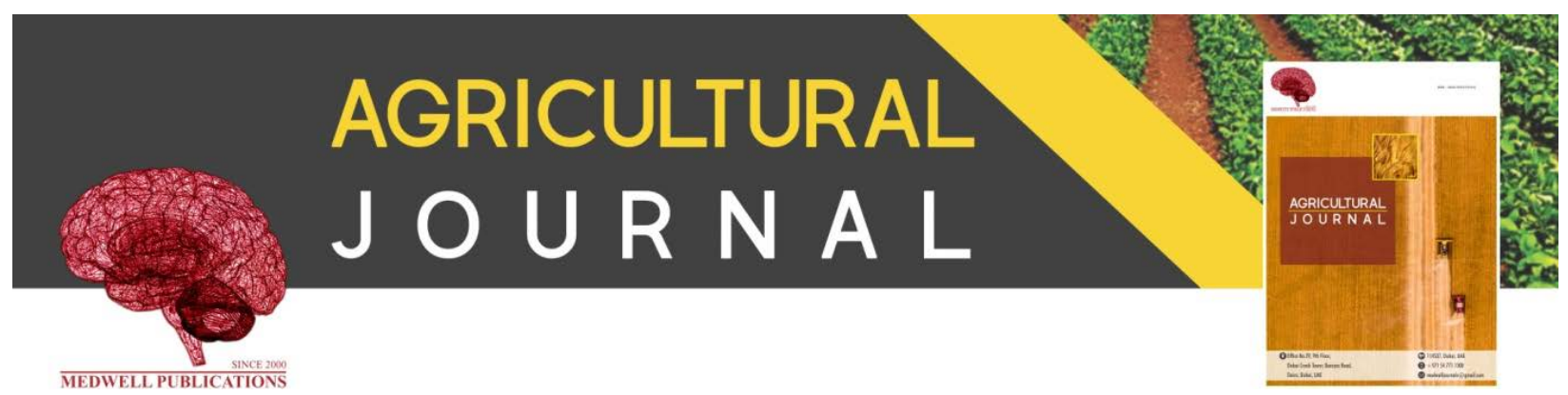

\title{
IoT-based Monitoring and Controlling of Crop Field and Induction Motor Protection from Voltage Fluctuation
}

\author{
Chandra Prakash and Rakesh Kumar Saini \\ School of Computing, DIT University, Dehradun, Uttarakhand, India
}

Key words: IoT, Agriculture, crop field, induction motor, sensors, soil moisture, temperature

Corresponding Author:

Chandra Prakash

School of Computing, DIT University, Dehradun, Uttrakhand, India

Page No.: 49-56

Volume: 15, Issue 4, 2020

ISSN: 1816-9155

Agricultural Journal

Copy Right: Medwell Publications
Abstract: The impassable use of technologies contributes to on condition that the accurate amount of water needed by plants. Agricultural country like India where more than $70 \%$ of rural population depends on farming and contributes around 18\% to the GDP. Despite of having modern facilities, farmers are still using traditional methods for irrigation. The main reason is the lack of knowledge and the cost of resources are too high which cannot bear by the farmers. It is mostly seen that the farmer uses ground water for irrigation. The management of ground water for irrigation is essential, while contributing to environmental sustainability. Here the word management is to irrigate more and more using the least water. IoT technologies can be a better option to achieve this goal. IoT technology is used in management of ground water for irrigation in the agriculture. But the commonality of the same thing has been found in all systems, i.e., the farmer has to buy lots of equipment's to apply the smart irrigation. This paper implements a gadget that provide information of the crop situation like degree the resistance or conductivity across the soil matrix among two contacts are basically junk, soil disease sensor regulates while the seeds will germinate and how rapid your flowers will develop in step with those data, microcontroller take the motion in form of induction motor gets ON/OFF when it's far required. This paper is also aim to shield 3 phase induction motor from inrush currents on the spreading device like fluctuations and single phasing.

\section{INTRODUCTION}

Right from the beginning, agriculture is contributing a big share to our country's income. Agriculture and allied activities contribute $18 \%$ of the total income while agriculture in other countries like UK and US contributed only 3\% of their total income. Agriculture consumption of freshwater in the world is about $70 \%{ }^{[1]}$ which makes a major concern issue to do smart irrigation management in instruction to recognizance nourishment and water security to the world's populace. For the cultivation of crops on-field irrigation system and application plays a 
Agric. J., 15 (4): 49-56, 2020

concern role. Unfortunately, in today world, many of the farmers are still using the traditional methods of irrigation which cause in low yielding of crops. In an effort to avoid the loss of productivity due to less irrigation, farmers shed access water and the result is not only challenged the productivity but also water and energy is wasted.

As the population is increasing, population of the world is increase by 2 billion in the coming 30 years and to feed such billions of people, there is a need to moderate the production. It is also fact that Population is increasing and agricultural land is decreasing day by day because of several reasons like industrialization and residential buildings are being constructed on agricultural fields. The Internet of things emerges as an excellent alternative to natural resources for doing smart irrigation to achieve the goal of increasing productivity ${ }^{[2]}$. The embossing of Internet of Things is an event caused by a combination of many factors such as affordable devices, availability of less-power wireless technology, cloud based storage, computational intelligence algorithms and computing resources in high-performance commodity platforms.

Currently, some challenges are still remaining to overcome comprehensive use of IoT for smart irrigation. First, IoT based applications are not yet fully automated ${ }^{[3]}$. Second, information models and adequate protocols are still requiring to integration of the sensors and actuators. Third, to automate the part of the process for implementing applications for smart irrigation.

In rural areas of India, the direct-on-line starters are used to start and drive the induction motors that provide a broad kind of defenses in contradiction of power variations and solitary phasing. This can be harmful for induction motors that can burn in seconds due to this until the power cannot be off. There is a need of making a protective device with programmable timer that can prevent the motor under such situations and also can perform action according to the data collected from different sensors.

This study presents a scenario-based development process of the system, its structure, framework and derived systems. Therefore, this paper proposes a device that is valuable in observing crop data as well as regulatory field processes that delivers tractability. The study aims to make agriculture smarter using automation and IoT technologies. The main features of system which is describe in this paper include GSM based remote controlling of real-time field operations which perform functions like humidity sensing and maintenance, temperature sensing and maintenance and protections against voltage fluctuations and single phasing.

Initially, this framework was introduced for home-based garden computerization using by Arduino and ZigBee components. Water is supplied to the roots of plants through dripped irrigation via solenoid valves. It is a traditional method, it involves the person initiating the process through the app and the command is passed to Arduino via. the ZigBee module. Based on the info received from the user the relay stimulates the pump on and off. Water is transported from the container through the solenoid valve to the roots of the plant in the garden.

Literature review: M.K. Gayatri, J. Jayasakthi, G.S. Anandha Proposes a method consolidating the benefits of the characteristics of growing technologies for example, Internet of Things (IoT) and Web Services that allows you to build a productive way to cope with the big facts related to agrarian yield. The methodology utilizes the aggregate of IoT and cloud computing that advances the quick improvement of horticultural modernization and assists with acknowledging savvy implementation for agricultural and proficiently address the issues associated with farmers ${ }^{[4]}$.

Paparao Nalajala, D. Hemanth Kumar, P. Ramesh and Bhavana Godavarthi provides the technical implementation in WSN made it viable to use in monitoring and control of greenhouse quantifiable elements in exactness agriculture. They were utilized ZigBee protocols based totally on IEEE 802.15. The climatic situations are checked and managed on-line by way of using Ethernet IEEE 802.3 $3^{[5]}$.

Carlos Kamienski, Juha-Pekka Soininen, Markus Taumberger, Ramide Dantas, Attilio Toscano, Tullio Salmon Cinotti, Rodrigo Filev Maia and André Torre Neto develops SWAMP system an IoT-based water management platform for accuracy water device in agriculture dependent on four pilots in Europe and Brazil. They introduce the SWAMP structure, platform and framework companies that feature the replicability of the platform. Scalability is an enormous concern for IoT applications, it includes a performance evaluation of FIWARE segments applied in SWAMP Platform. Results show that it could deliver enough performance to the SWAMP pilots but requires highly based designs and the re-building of sure segments to provide higher versatility making use of much less computational assets ${ }^{[6]}$.

An irrigation device framework became created to improve water use for vegetation. The framework has an appropriated Wi-Fi system of soil-moisture and temperature-sensors set to root of the plant. Likewise an entryway unit handles sensor statistics, triggers actuators, and transmits records to a web application. An algorithm was advanced with set envisioned values of temperature and soil-moisture that changed into programmed right into a microcontroller to control water quantity. The framework changed into powered through photovoltaic boards and had a duplex correspondence connect dependent on a Cellular-Internet interface that took under consideration data evaluation and irrigation scheduling to be programmed through a website web page ${ }^{[7]}$. 
A framework is designed to test crop-field using sensors and to automatize the irrigation system. The statistics from sensors are sent to the API database utilizing Wi-Fi transmission. The statistics can be imagined at the evolved Web page in which the readings from the sensors can be seen. The records are encoded in JSO Notation format. The irrigation machine is robotizing in that device is possibly empowered while the soil moisture of the field falls all the way down to the set values. An alert message is dispatched intermittently to the net web page dashboard and cell software. The farmer can see the sector conditions anyplace, each time ${ }^{[8]}$.

Agbo et al..$^{[9]}$ advanced a device that shields 3phase induction motor from inrush currents like voltage fluctuations and unmarried phasing by using PIC16F84A Microcontroller. They shape a circuit of a programmed starter; its miles intended to be utilized associated with a direct on-line starter. Programmed start on resumption of suitable situations Single phasing avoidance $24 \mathrm{~h}$ programmable off clock ${ }^{[9]}$.

\section{MATERIALS AND METHODS}

Proposed system: Internet of Things is stimulating the farming with innovation, extensive correctness and conventional farming to go in contradiction of the challenges in farming. IoT assists information on conditions like temperature and soil conditions, atmosphere, water level, animal intervention in the area, changes in agri-cultivation. IoT provide farmers to monitor and control wherever and at any point to relate their habitat. This uses to examine field circumstances and minor-measure controllers are used to regulate ${ }^{[10]}$.
Block diagram of proposed system: The design of the planned system is shown in Fig. 1. A 9V power is supplied to the microcontroller and other components such as sensors and modules. It is a switching AC/DC supply. It is thin so it can fit into the power strips without blocking other outlets. The 5.5/2.1 mm barrel jack, positive tip. The Productivity is structured so that we get a continuous $9 \mathrm{~V}$ up to $1000 \mathrm{~mA}$ (1 Amp).

THERM-200 soil temperature ensor is directly connected to microcontroller and accurately measures the temperature profile of the soil close to its surface. The $\mathrm{VH}-400$ is a lowcost soil moisture sensor used to check soil water content and its result is save to the amplifier which is used to improve the gain-value and this measured value is given to the microcontroller as an analog input. Microcontroller convert analog input to digital output values to perform actuator action in form of motor start or stop according to set values.

The DHT22 is digital temperature and humidity sensor uses a capacitive humidity sensor. DHT22sensor is used to measure the surrounding air and gives a digital signal to the data pin.

CDS photo resistor cells are small light sensors. When its light, resistance goes about $\sim 1 \mathrm{~K}$ when dark it goes up to $\sim 10 \mathrm{~K}$. The output from Arduino is given to driver circuit and also given to the farmers by GSM module. Based on the information given to the driver circuit the induction motor gets ON/OFF when it is required. Farmers also can take the action manually as per the information received from Arduino via. GSM module (Fig. 1).

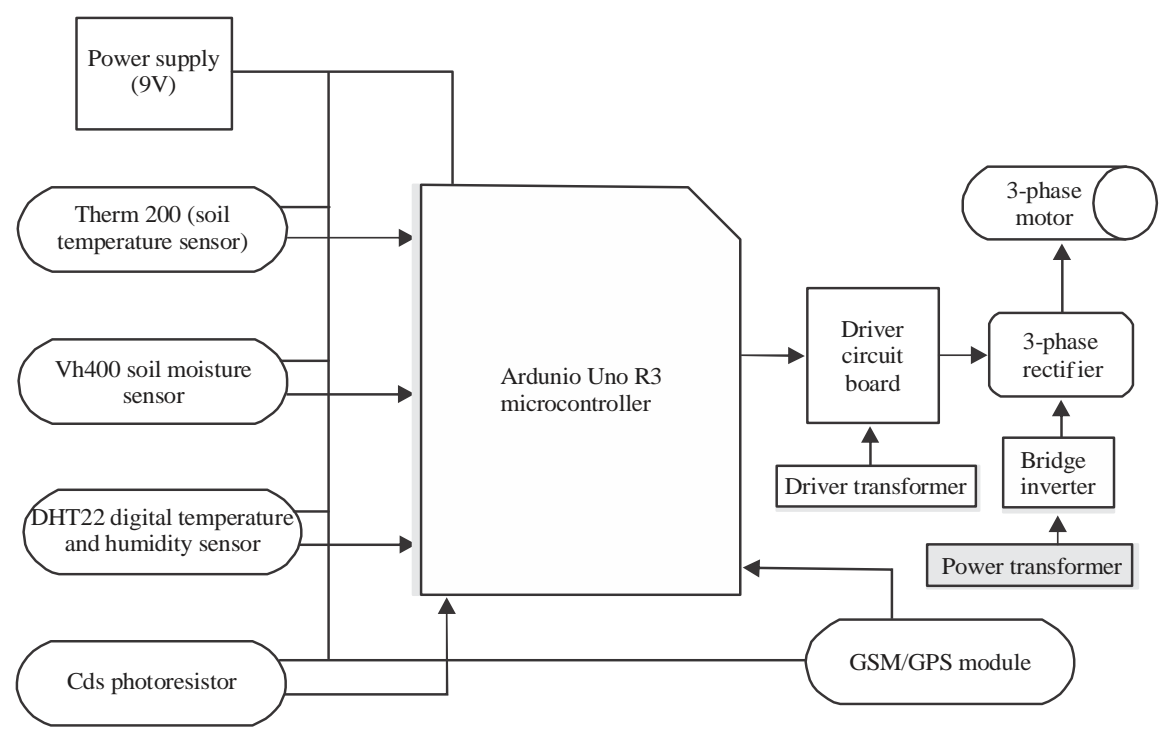

Fig. 1: Proposed system 


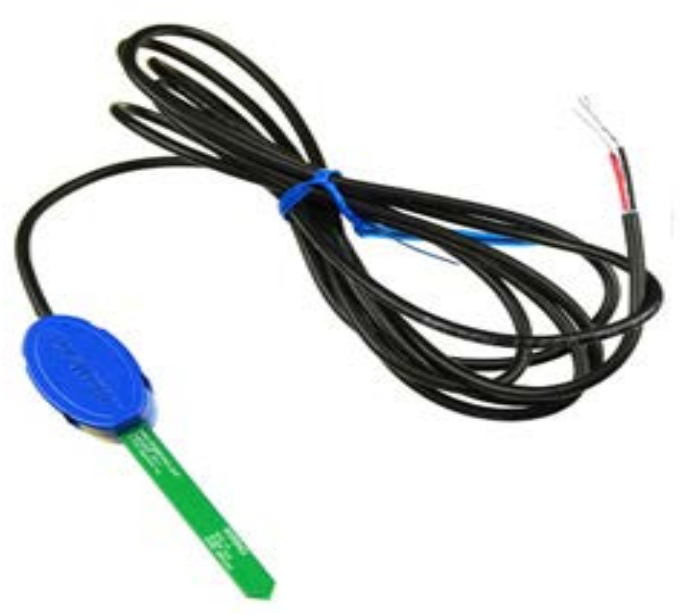

Fig. 2: Therm-200 soil temperature sensor

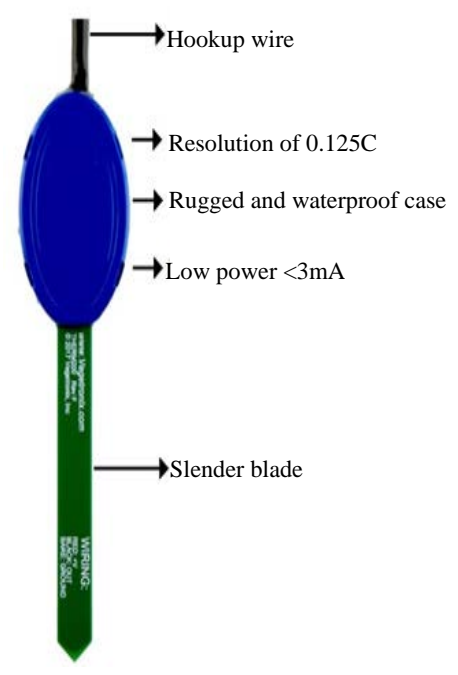

Fig. 3: Therm-200 probe features1

THERM-200-soil temperature sensor: The THERM-200 soil temperature sensor may be very low cost, low strength, small in size, may be buried and is water evidence. It consumes $<3 \mathrm{~mA}$ for extremely low power operation when activated.

THERM-200 measurement gives accurate measure to take action. THERM-200 may be operated in brief before analyzing and then shut all the way down to conserve the battery strength. THERM-200 Probe is lengthy and slim for wider use such as smaller potted plant. The THERM-200 soil temperature sensor can be together used with soil moisture sensors to analyze the presence of water (Fig. 2).

The THERM-200 soil temperature sensor determines while the seeds will germinate and the way speedy the plant will grow. THERM-200 soil temperature sensor

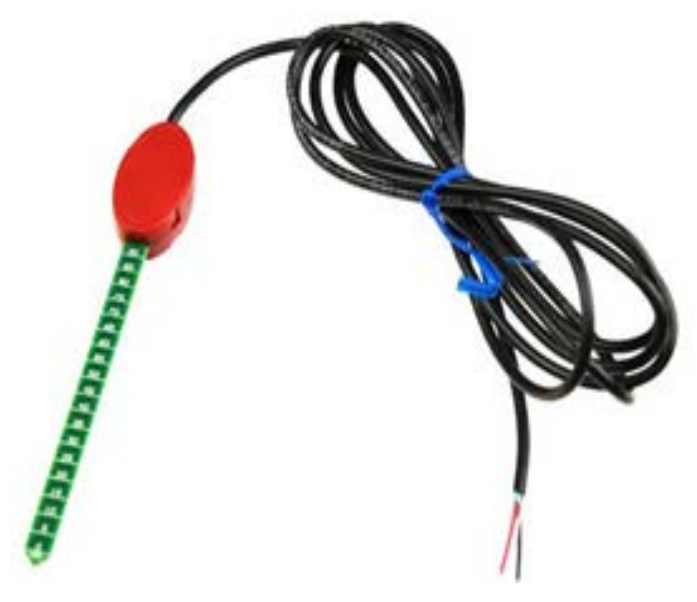

Fig. 4: VH-400 soil moisture sensor

helps to guard plants and quicklyanalyze crop field problems. When used with the GSM module, we can receive text messages and alerts to know the plants having trouble with temperature extremes. The temperature sensor is notably correct with $0.125 \mathrm{C}$. THERM-200 temperature sensor is made from long lasting ABS plastic and fiberglass and truly water proof and rugged Fig. 3.

VH-400-soil moisture sensor: The VH-400 is a soilmoisture sensor used to measure the quantity of water in soil. This soil-moisture sensor is water-proof and may be buried at any depth. The roots are not disturbing due to its thin structure of blade. It can perform with low power battery operation. It gives precise and accurate measurement and can analyze VWC\&GWC. It can measure the moisture to your hands when you put your hands on its blade. VH-400 temperature sensor is made of durable ABS plastic and fiberglass and absolutely water proof and rugged.

Because of salts and fertilizers determined in soil, maximum of other devices is infective, specifically from conductivity or resistance. But VH-400 uses superior transmission line strategies to measure the water moisture in any kind of soil irrespective of soil salinity. Unlike resistive or conductivity sensors, the $\mathrm{VH}-400$ s do no longer use uncovered probe to make measurements. The blade of the sensor can be inserted into soil and pots with minimum disturbance to the critical root constructions of plants (Fig. 4).

VH-400 is super fast sensor as compare to other soil moisture sensors. The output response is get as quickly as with changes in water moisture. When we irrigate the crop field, we can easily observe the 
Agric. J., 15 (4): 49-56, 2020

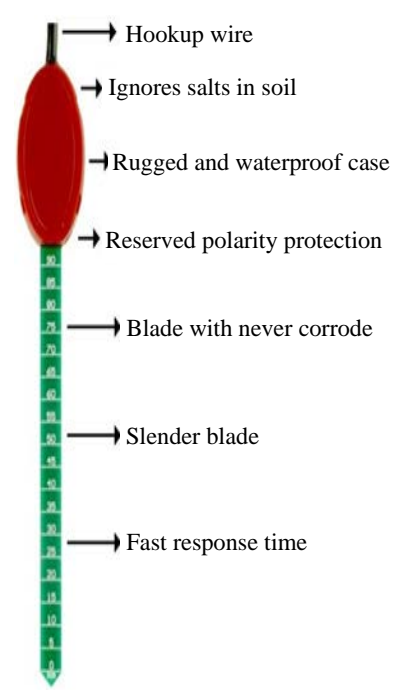

Fig. 5: VH-400 probe features

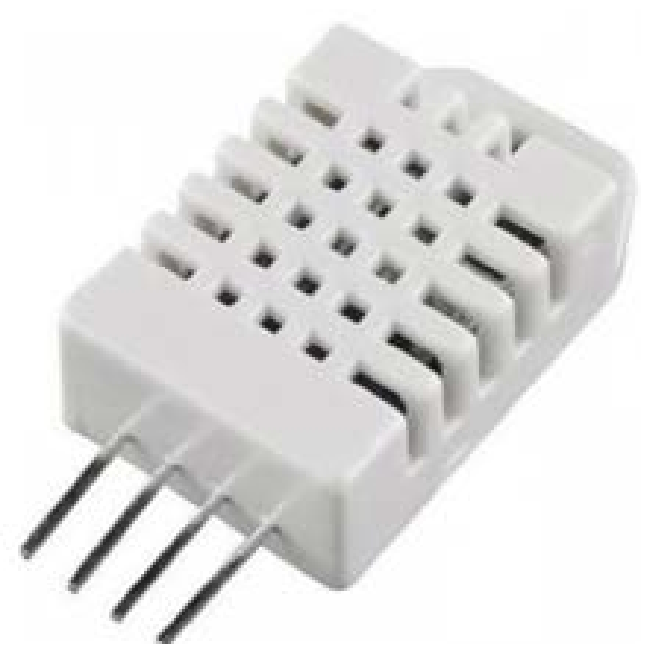

Fig. 6: DHT-22 temperature-humanidity sensor

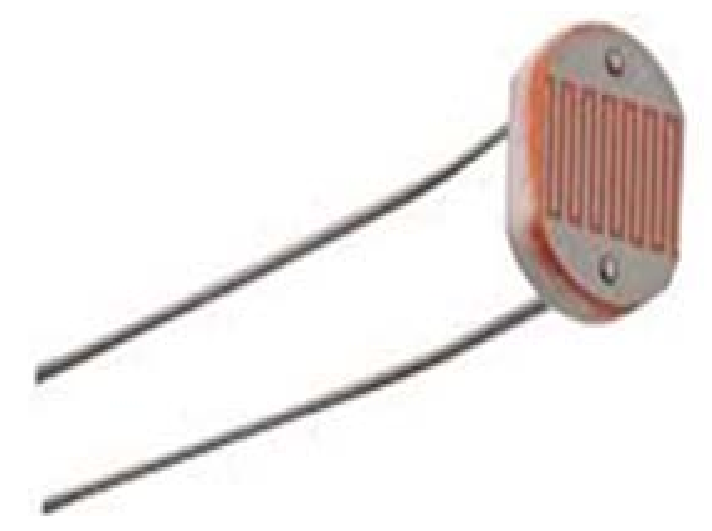

Fig. 7: CdS photo-resistor moisture chances in real-time. This fast response time allows us to check the moisture of soils and plants by way of sliding into the blades and takes the measurements. The $\mathrm{VH}-400$ can operate in extremely low power can effectively works with $12 \mathrm{~mA}$ while activated. Like THERM-200 sensor, VH-400 can take the reading when activated and then off to save the power of batteries. VH-400 can replace sprinkler rain sensors, stop spraying water when soil is moist monitoring flooding and defend concrete foundations with the aid of keeping good soil moisture (Fig. 5).

DHT-22 temperature-humidity sensor: DHT-22 is a ow-price temperature and humidity sensor. It utilizes a thermistor and also a capacitive humidity sensor to analyze the encircling air and gives digital signal to the data pin.

DHT-22 sensor is very easy to use however, it requires careful time to seize the data. The best real aspect of this sensor is that you can get new data from it as soon as in 2 seconds only. Simply connect the primary pin to the left side with 3-5V strength, the second one pin to data input pin and the right side pin to the GND (Fig. 6).

CdS Photo-resistor: CDS photo resistor cells are small-light sensors. Because of the squiggly face of CdS turns to exposed more light, the resistance is decreases. Resistance goes up-to $\sim 1 \mathrm{~K}$ and $\sim 10 \mathrm{~K}$ when its light and dark, respectively. Connect one side of the CDS cell to the power and the other side of the cell is connected to the analog input pin of microcontroller and then connect a pull-down resistor of $10 \mathrm{~K}$ from that analog pin to GND. When its light out, the voltage on the pin will be $2.5 \mathrm{~V}$ or higher and near ground when its dark (Fig. 7).

\section{RESULTS AND DISCUSSION}

As in the introduction part, basically this system comprises two sub system. One sub system is used to collecting field information and also perform operation based on that collected information like GSM based smart controlling of irrigation with real-time field data collected by various sensors, controlling of temperature and humidity and also detection of intervention of suspected person to theft the irrigation equipments. Another sub system comprises of protection against voltage fluctuations and single phasing. Figure 7 shows the integrated circuit diagram of the system which contains two sub system.

THERM-200 Sensor, VH-400 Sensor and CDS cell are connected to the input (analog) pins of Arduino 
Agric. J., 15 (4): 49-56, 2020

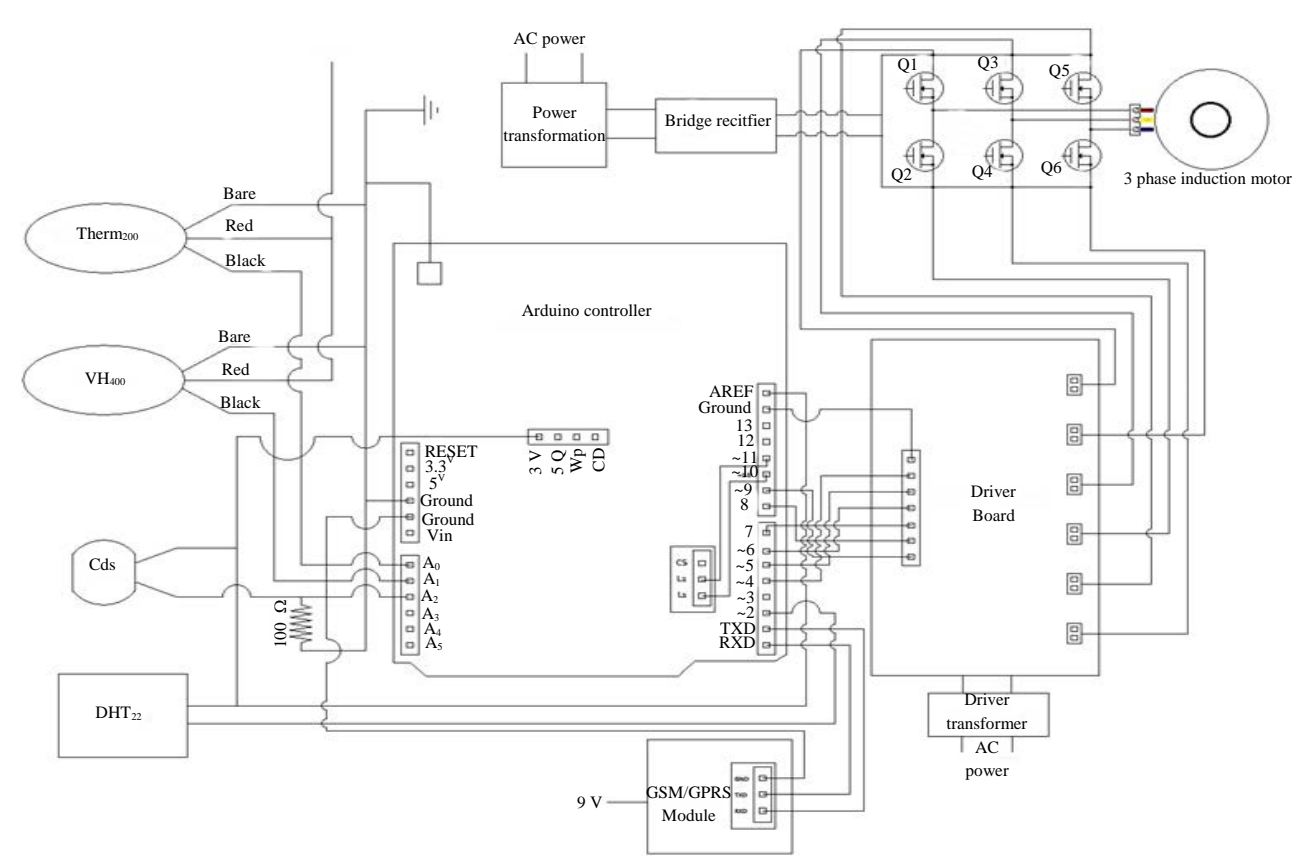

Fig. 8: Circuit diagram of the system

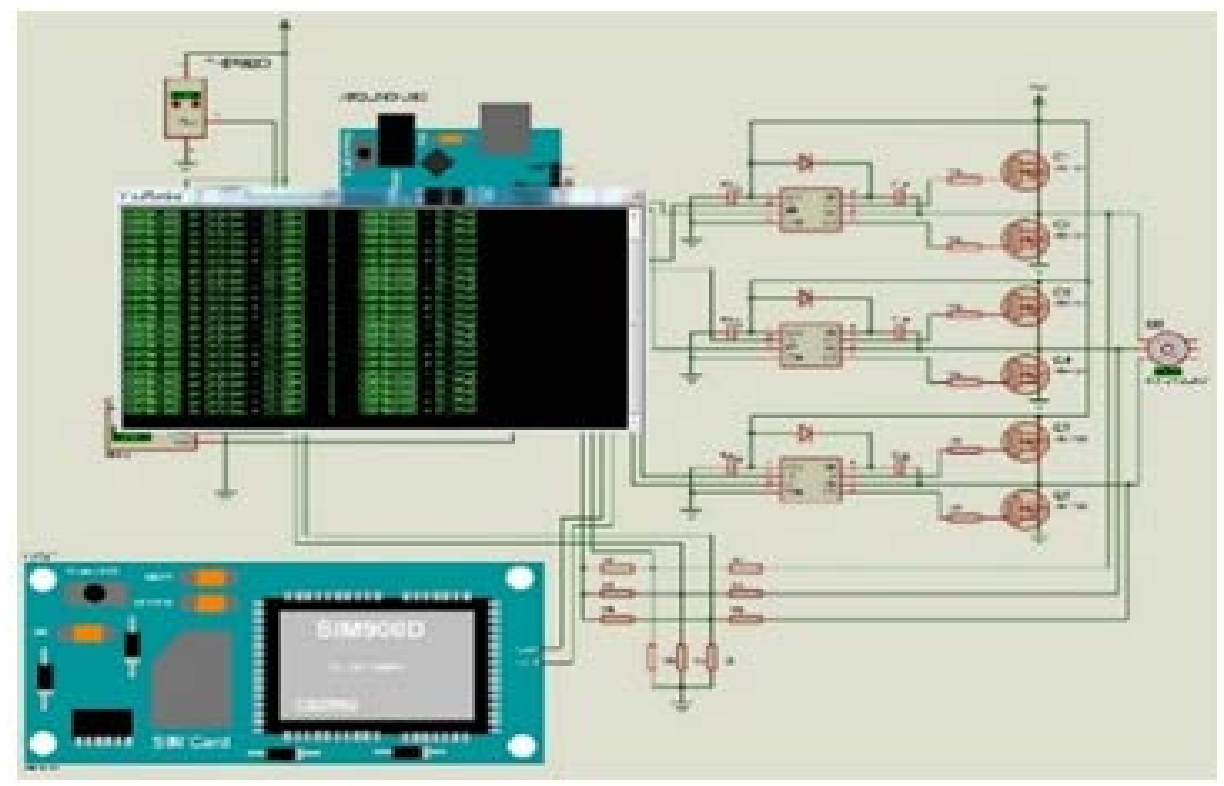

Fig. 9: Simulation in Proteus showing temperature and moisture in soil

microcontroller. These sensors get the information associated to crop-field and transmitted to the microcontroller. Microcontroller perform operations such as ON/OFF 3-phase induction motor if the crop soil is wet is below to the set values and send the information to farmer to take action manually. The information is send to farmer by GSM module via SMS alert (Fig. 8 and 9).
When the device is initially switched ON, take few seconds to guarantee that the power source is steady and afterward begins observing. By turning the relay's ON/OFF, the microcontroller turns-on relay's LED. When relay's LED turned on, it means that the 3-phases are either ON or OFF. Microcontroller continuously takes the input from 3 mains through step-down transformers. The 


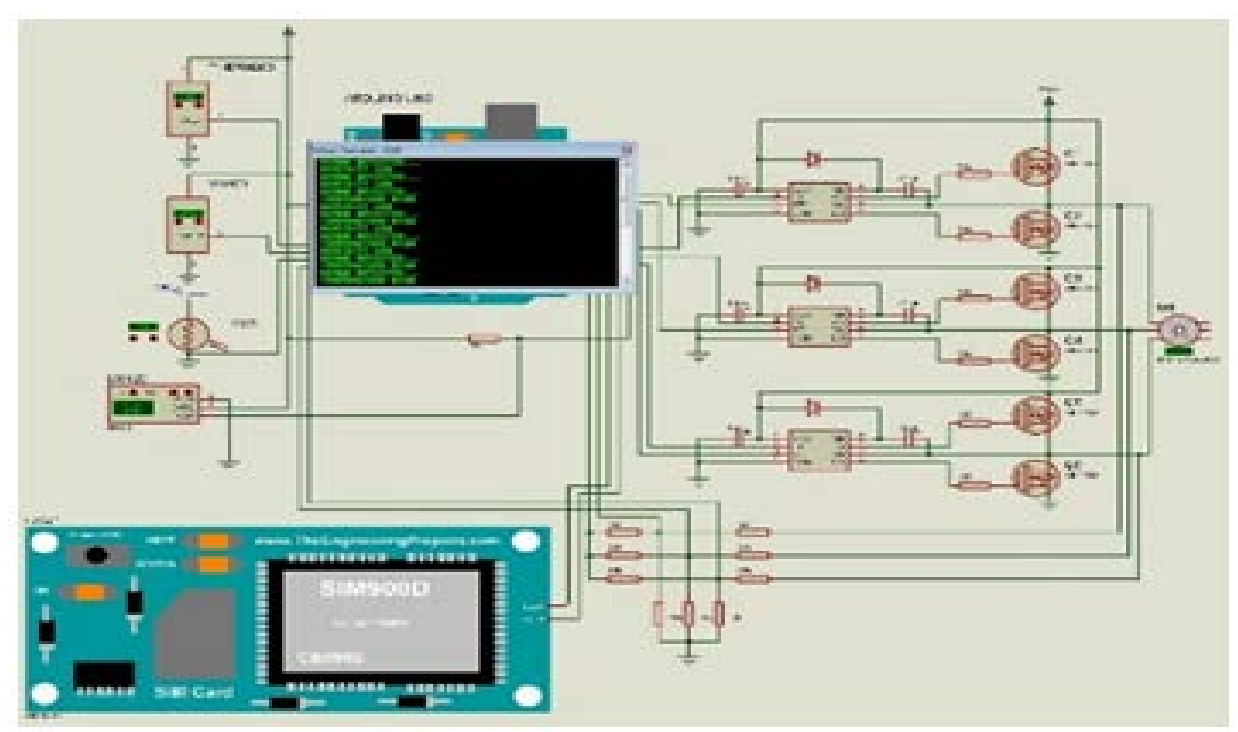

Fig. 10: Simulation in proteus for taking action according to analog signal received

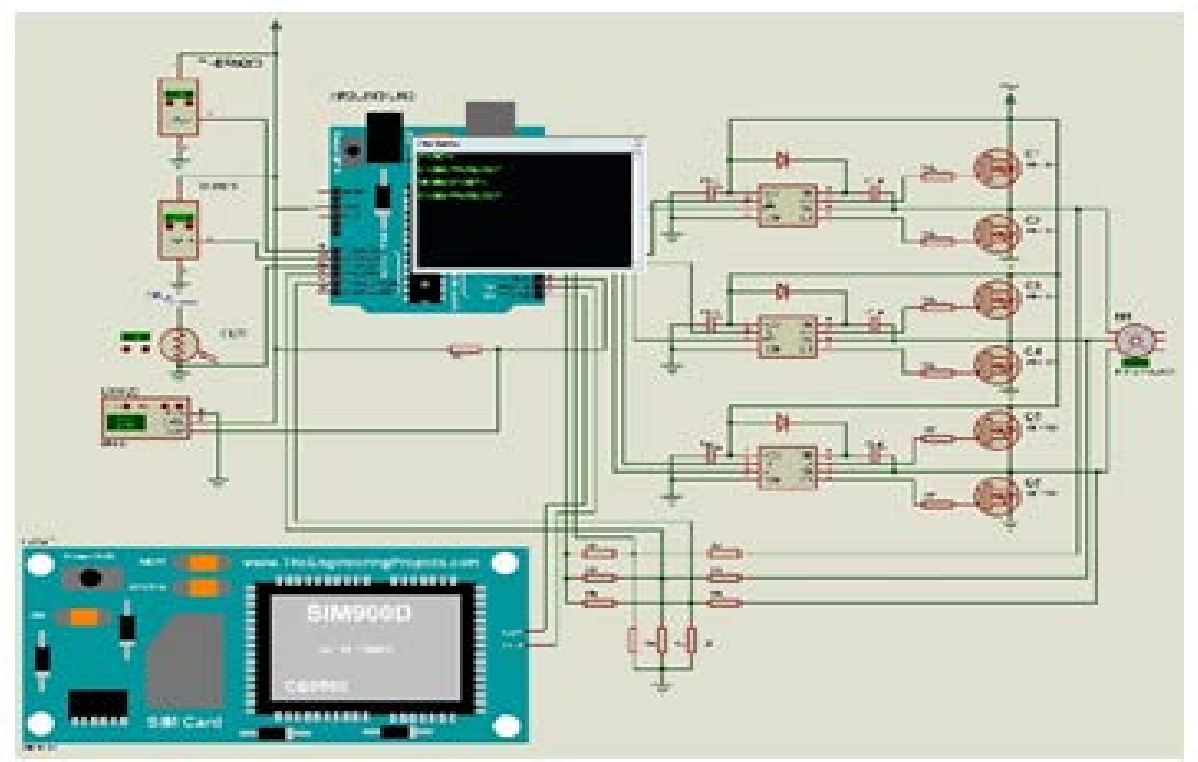

Fig. 11: Simulation in proteus for taking action according to voltage fluctuations and single phasing

code programmed in the memory of microcontroller turns the 3-phase relays ON/OFF and turns LED either Green or RED (Fig. 10 and 11).

\section{CONCLUSION}

The proposed system is simulated in Proteus and capable enough for analyzing/observing, gathering and recording the data of crop field by various sensors used and perform actions according to the programmed values in microcontroller. The data which is stored can be used for future research. This system takes the action to automate the irrigation when the values of the different parameter like temperature and moisture are falls below the brink in the program which is embedded in the microcontroller without any human intervention or a farmer can also be able to take the decision manually according to data receive via. SMS. This system is also providing the protection of induction motor from voltage fluctuations and single phasing. An under/over voltage fluctuation shield system and single phasing system has been developed as a programmable unit in 3-phase 
Agric. J., 15 (4): 49-56, 2020

motor-starter that is required to monitor the current supply to 3-phase motor and accordingly protect the motor from voltage fluctuations and single phasing. This system is cost effective, so that, the farmers can afford it. Lack of less access to internet connection in some remote location of farms, this system is initially configuring on GSM module for sending SMS to farmers but can be reconfigure to access the data at anywhere by using cloud technology. The decision making component of this system are able to automate the irrigation process, so that, the farmer's manual work with the irrigation process will be less and this will advance to minimize human manual work for the crop-field monitoring process and controlling process.

\section{REFERENCES}

01. FAO., 2016. AQUASTAT-FAO’s global information system on water and agriculture: Water uses. Food and Agriculture Organization, Rome, Italy.

02. Atzori, L., A. Iera and G. Morabito, 2010. The internet of things: A survey. Comput. Networks, 54: 2787-2805.

03. Kamienski, C., M. Jentsch, M. Eisenhauer, J. Kiljander and E. Ferrera et al., 2016. Application development for the Internet of Things: A context-aware mixed criticality systems development platform. Comput. Commun., 104: $1-16$.
04. Gayatri, M.K., J. Jayasakthi and G.S. Anandhamala, 2015. Giving smart agriculture solutions to farmers for better yielding using IoT. Proceedings of the IEEE International Conference on Technological Innovations in ICT for Agriculture and Rural, July 10-12, 2015, IEEE, Chennai, India, pp: 40-43.

05. Nalajala, P., D.H. Kumar, P. Ramesh and B. Godavarthi, 2017. Design and implementation of modern automated real time monitoring system for agriculture using Internet of Things (IoT). J. Eng. Appl. Sci., 12: 9389-9393.

06. Kamienski, C., J.P. Soininen, M. Taumberger, R. Dantas and A. Toscano et al., 2019. Smart water management platform: IoT-based precision irrigation for agriculture. Sensors, Vol. 19, 10.3390/s19020276

07. Gutierrez, J., J.F. Villa-Medina, A. Nieto-Garibay and M.A. Porta-Gandara, 2013. Automated irrigation system using a wireless sensor network and GPRS module. IEEE. Trans. Instrum. Meas., 63: 166-176.

08. Ogunti, E., 2019. IoT based crop field monitoring and irrigation automation system. IJISET-Int. J. Innovative Sci. Eng. Technol., 6: 124-129.

09. Agbo, D.O., D.T. Kureve and D.H. Shittu, 2014. Implementation of an automatic induction motor starter with delay using microcontroller. Int. J. Sci. Technol. Res., 3: 47-51.

10. Gondchawar, N., 2016. IoT based agriculture all-embracing almanac consisting of contemporary analysis smart minicomputer additionally conversation planning. Overall J. Recent Innovation Trends Comput. Commun., 5: 177-181. 